\title{
GLP-1: benefits beyond pancreas
}

\author{
G. Muscogiuri - A. Cignarelli $\cdot$ F. Giorgino $\cdot$ F. Prodram $\cdot$ D. Santi \\ G. Tirabassi $\cdot$ G. Balercia $\cdot$ R. Modica $\cdot$ A. Faggiano $\cdot$ A. Colao
}

Received: 9 April 2014/ Accepted: 10 July 2014/Published online: 9 August 2014

(C) Italian Society of Endocrinology (SIE) 2014

\begin{abstract}
Introduction Glucagon-like peptide 1 (GLP-1) is an intestinal hormone secreted after the ingestion of various nutrients. The main role of GLP-1 is to stimulate insulin secretion in a glucose-dependent manner. However, the expression of GLP-1 receptor was found to be expressed in a variety of tissues beyond pancreas such as lung, stomach, intestine, kidney, heart and brain. Beyond pancreas, a beneficial effect of GLP-1 on body weight reduction has been shown, suggesting its role for the treatment of obesity. In addition, GLP-1 has been demonstrated to reduce cardiovascular risk factors and to have a direct cardioprotective effect, fostering heart recovery after ischemic injury. Further, data from both experimental animal models and human
\end{abstract}

G. Muscogiuri $(\bowtie) \cdot$ R. Modica $\cdot$ A. Faggiano $\cdot$ A. Colao Section of Endocrinology, Department of Clinical Medicine and Surgery, University "Federico II", Via Sergio Pansini, 5, Naples, Italy

e-mail: giovanna.muscogiuri@gmail.com

A. Cignarelli · F. Giorgino

Section of Internal Medicine, Endocrinology, Andrology and Metabolic Diseases, Department of Emergency and Organ

Transplantation, University of Bari Aldo Moro, Bari, Italy

F. Prodram

Division of Pediatrics, Department of Health Sciences, University of Piemonte Orientale "A. Avogadro", Alessandria, Italy

D. Santi

Section of Endocrinology, Department of Biomedical, Metabolic and Neural Sciences, University of Modena and Reggio Emilia, Via Campi 287, 41125 Modena, Italy

G. Tirabassi - G. Balercia

Division of Endocrinology, Department of Clinical and Molecular Sciences, Umberto I Hospital, Polytechnic University of Marche, Ancona, Italy studies have shown beneficial effect of GLP-1 on bone metabolism, either directly or indirectly on bone cells.

Materials and methods We review here the recent findings of the extra-pancreatic effects of GLP-1 focusing on both basic and clinical studies, thus opening future perspectives to the use of GLP-1 analogs for the treatment of disease beyond type 2 diabetes.

Conclusion Finally, the GLP-1 has been demonstrated to have a beneficial effect on both vascular, degenerative diseases of central nervous system and psoriasis.

Keywords GLP-1 - Pancreas - Body weight · Cardiovascular system $\cdot$ Bone $\cdot$ Central nervous system

\section{Introduction}

Glucagon-like peptide 1 (GLP-1) is a gut-derived hormone that is secreted in response to oral nutrient intake, displaying a potent insulinotropic activity in several species, including humans [1]. To exert its biological effect, GLP-1 binds its specific GLP-1 receptor that is a G protein-coupled receptor family. Upon binding to its receptor, GLP-1 increases the intracellular cAMP levels stimulating insulin secretion in pancreatic beta cells in a glucose-dependent manner [2]. In addition, GLP-1 has been reported to have a beneficial effect per se on insulin resistance. D'Alessio et al. [3] investigated the effect of GLP-1 infusion in healthy subjects in which GLP-1 improved glucose tolerance both through its insulinotropic action and by increasing glucose effectiveness thus suggesting that GLP1 has direct effects on tissues involved in glucose disposition. The insulin sensitizer effect of GLP-1 may be due to a direct effect to recruit muscle microvasculature, to increase muscle delivery of insulin and to enhance muscle 
use of glucose [4] and may be indirectly mediated by the suppression of glucagon secretion that in turn results in a reduction of the hepatic glucose production $[5,6]$. Furthermore, GLP-1 inhibits gastrointestinal secretion and motility, including gastric emptying, induces satiety and reduces food intake, thus promoting weight loss and increasing insulin sensitivity [7, 8]. However, GLP-1 receptors have been found to be expressed in several tissues beyond pancreas, and in particular in lung, in the stomach, intestine, kidney, heart and brain [9]. Thus, several beneficial effects of GLP-1 have been reported beyond the glycemic control. In particular, GLP-1 has been demonstrated to have both a direct cardioprotective effect and indirect beneficial effect on cardiovascular risk biomarkers (blood pressure, cholesterol levels, postprandial triglyceride and glucose levels, coagulability, and inflammation) [10]. The improvement of cardiovascular biomarkers is also due to the effect of GLP-1 on obesity. In fact GLP-1 plays an important role in reducing the appetite and increasing satiety acting on different brain areas such as the hypothalamic nuclei, thalamus, hippocampus, lateral septum, and subfornical organ [11]. In addition, GLP-1 slows nutrient absorption decreasing postprandial production of apolipoprotein B-48 [12], decreasing gastric acid secretion in response to gastrin release and meal intake. GLP-1 also inhibits gastric emptying via vagal afferent-mediated central mechanisms [13]. The involvement of GLP-1 in bone metabolism comes from evidence obtained in knockout mice for GLP-1 receptor that shows a cortical osteopenia, bone fragility and increased bone resorption and osteoclast numbers [14]. These effects seem to be mostly mediated by the effect of calcitonin stimulated by GLP-1 since mice, by contrast to human subjects, express GLP-1 receptor on thyroid C cells [14]. However, clinical evidence in humans is still not enough to allow definitive conclusions. Finally GLP-1 has been shown to have beneficial effects on central nervous system and mostly to exert a neuroprotective effect in rodent models of stroke, Alzheimer's disease and Parkinson's disease [15].

Given this growing body of evidence that shows pleiotropic effects of GLP-1 in extra-pancreatic tissues, this article will review the preclinical and clinical evidence, focusing on the latest data, showing the effects of GLP-1 on the cardiovascular system, body weight, bone and central nervous system. This may allow a potential and future use of GLP-1 analogs' therapy as a multifactorial treatment for disease beyond type 2 diabetes (Fig. 1; Table 1).

\section{Distribution of GLP-1 and GLP-1 receptors}

Active GLP-1 is a peptide of 30 amino acids expressed and secreted by endocrine $\mathrm{L}$ cells of intestinal mucosa at the ileum and colon level. GLP-1 derives from the same precursor of glucagon through the cleavage action of proconvertase $1 / 3$. The proglucagon gene is localized on human chromosome 2q36-q37 and comprises 6 exons. In the gut, proteolytic processing of proglucagon generates GLP-1 and GLP-2, whereas glucagon is produced in the pancreas $[1,16]$. In the intestine, GLP-1 is produced as an inactive 37 -amino acid peptide. The active form is produced by post-translational cleavage of six amino acids from the N-terminal end of GLP-1 (1-37). The truncated peptides of GLP-1 (GLP-1 7-36 amide or GLP-1 7-37) are the active equipotent insulinotropic forms; however, in current literature, the unqualified designation GLP-1 covers only the truncated peptide [1]. In addition, almost all secreted GLP-1 is amidated at the glycine end of the C-terminal with an improved stability. Only $10-15 \%$ of secreted GLP-1 reaches systemic circulation in the intact form. This rapid initial whole body clearance is due to the liver metabolism and also to the activity of dipeptidyl peptidase-4 (DPP4) which is expressed in both enterocytes and endothelial cells of the lamina propria capillaries [1].

Three hormonal products, GLP-1, GLP-2 and oxyntomodulin, arise from its processing in neurons. GLP-1 secreting neurons are mainly located in the hindbrain nucleus of the solitary tract suggesting that GLP-1 plays a role in the control of food intake $[1,17]$. GLP-1 cells in the nucleus of the solitary tract stick out throughout the brain to other nuclei involved in energy homeostasis (e.g., the paraventricular, the dorsomedial and the arcuate nucleus of the hypothalamus), and also to nuclei associated with reward and motivation such as the ventral tegmental area and the nucleus accumbens $[18,19]$.

GLP-1 receptor (GLP-1R) belongs to the Gsproteincoupled receptor (GPCR) family which activates downstream pathways including cAMP/protein kinase A (PKA), cAMP/guanine-nucleotide exchange factor (Epac) or phosphatidylinositol-3 kinase/PKC pathways. Classically, GLP-1Rs are ubiquitous being found with the highest expression in $\beta$ - and $\delta$-cells of the pancreas and lungs, and the less expression in parietal cells of the stomach, pylorus, adipose tissue, heart, kidney, pituitary and the brain $[1,20]$. However, using a new monoclonal antibody for immunohistochemistry and by confirmation with binding studies, in humans and monkeys it has been recently shown that in the pancreas, GLP-1R protein was predominantly localized in $\beta$-cells and, weakly in acinar cells without expression in pancreatic ductal epithelial cells. In the kidney and lung, GLP-1R protein was exclusively expressed in smooth muscle cells of arteries and arterioles within a consistent expression in renin-secreting cells of the juxtaglomerular apparatus. In the gut, the highest GLP-1R protein expression was detected in the Brunner's gland in the duodenum, with lower level expression in parietal cells and in 


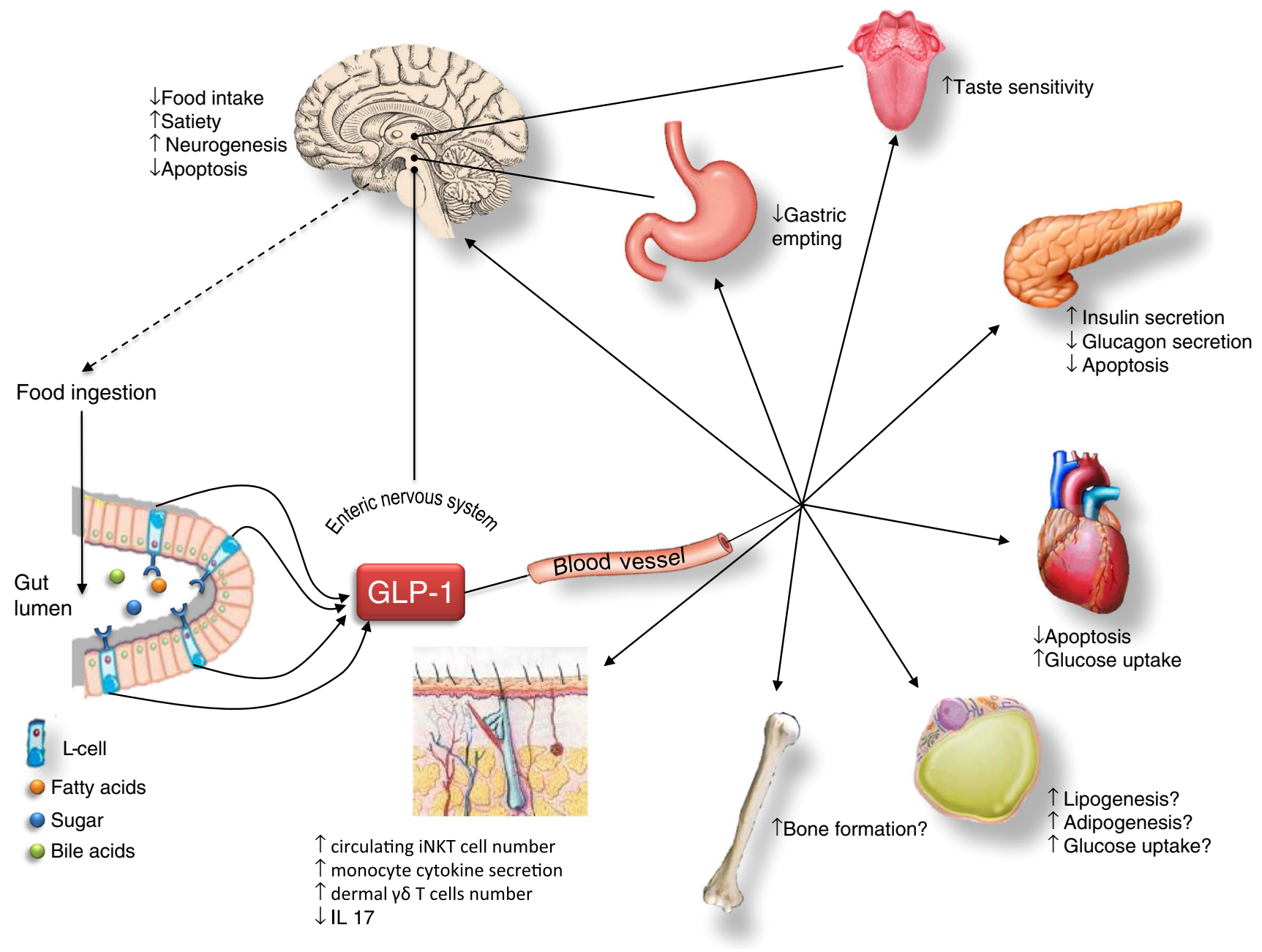

Fig. 1 Physiology of Glucagon-like peptide-1 (GLP-1) secretion and action on extra-pancreatic organs and tissues. Various organs affected by GLP-1 actions are depicted in the figure. GLP-1 is released postprandially by intestinal L cells. In the stomach, GLP-1 slows motility resulting in delayed gastric emptying. In the central nervous system (CNS), GLP-1 is an important neurotransmitter for regulating appetite, taste sensitivity and eating behavior. GLP-1 promotes satiety and leads to reduced food intake and body weight. Additional longterm effects of GLP-1 on the CNS comprise an improvement of

myenteric plexus neurons. In the heart, GLP-1R protein was localized in myocytes of the sinoatrial node [9]. It has been also demonstrated both as mRNA and protein in macrophages and monocytes $[9,21]$. It has to be noted that GLP-1R expression presents differences among the species, first of all no staining has been demonstrated in primates in thyroid, and in the liver, whereas its expression is much lower in humans than in rodents in C cells [9]. More recently, in rodents and mammals, the expression of GLP-1 protein has been identified in taste cells and that of GLP-1R in adjacent taste nerve fibers [22], suggesting that the system may act with an alternative and intriguing way on food intake. learning and memory, as well as a stimulation of neurogenesis. In the heart, GLP-1 has preventive effects on cardiac cell apoptosis and ischemic damage. GLP-1 appears to promote bone formation and to inhibit bone resorption, also resulting in an improvement of bone strength. Moreover, GLP-1 release potentially exerts anabolic effects on adipose tissue. Finally GLP-1 seems to increase circulating iNKT cell number, to modulate monocyte cytokine secretion, to decrease of dermal $\gamma \delta$ T cells number and IL-17 expression

Although their primary sequence is identical and until now no GLP-1R subtypes have been identified, all the GLP-1Rs in different tissues have similar but not identical ligand-binding capacity to GLP-1 maybe due to posttranslational modifications as glycosylation [23]. Furthermore, their sequence seems to be homologous to these sequences of the family of $G$ protein receptors for several other endocrine peptides such as glucagon, secretin, calcitonin, GHRH, PTH and vasoactive intestinal peptide [1]. Some evidence, in particular in myocardium, osteoblasts and lymphocytes models, also suggests that extra-pancreatic effects of GLP-1 could be mediated by receptors other than the "classical" GLP-1 receptor [24-26]. Furthermore, 
Table 1 Effects of Glucagon-like peptide-1 (GLP-1) on extra-pancreatic organs and tissues

\begin{tabular}{|c|c|c|}
\hline \multirow{2}{*}{$\begin{array}{l}\text { GLP-1 } \\
\text { target }\end{array}$} & \multicolumn{2}{|l|}{ Effect } \\
\hline & $\downarrow$ & $\uparrow$ \\
\hline \multirow[t]{2}{*}{ Brain } & Food intake & Satiety \\
\hline & Apoptosis & Neurogenesis \\
\hline Tongue & & Taste sensitivity \\
\hline Heart & Apoptosis & Glucose uptake \\
\hline Stomach & Gastric emptying & \\
\hline \multirow[t]{3}{*}{ Adipocyte } & & Lipogenesis? \\
\hline & & Adipogenesis? \\
\hline & & Glucose uptake? \\
\hline Bone & & Bone formation? \\
\hline \multirow[t]{3}{*}{ Skin } & Cytokine secretion & $\begin{array}{l}\text { Circulating iNKT cell } \\
\text { number }\end{array}$ \\
\hline & $\begin{array}{l}\text { Dermal } \gamma \delta \mathrm{T} \text { cells } \\
\text { number }\end{array}$ & \\
\hline & IL-17 expression & \\
\hline
\end{tabular}

the GLP-1 (9-36), which is classically considered as an insulinotropic-inactive metabolite, shares some of the cardiac effects of the "active" GLP-1 (7-36), at least in rodents [25].

It appears clear as the widely distribution of GLP-1, and even more of GLP-1R justifies the pleiotropic actions discussed below (Fig. 1; Table 1).

\section{GLP-1 and central nervous system}

GLP-1 receptors are present in several regions of the brain, especially in the ones controlling appetite and satiety [27] as already described. In this regard, one of the effects of GLP-1 receptor agonists' administration is the body weight reduction [28]. This effect seems to be mediated by reducing appetite and promoting satiety and, at the same time, by acting on energy expenditure and thermogenesis [29]. Such actions on the central nervous system may occur both by direct and indirect pathways. Indirect circuits have a greater effect and they involve hepatic and gastrointestinal vagal fibers in which GLP-1 receptors have been identified [30]; in fact, several experiments conducted in vagotomised animals showed no reduction in food intake or lack of neuronal activation in several brain areas related to eating control after GLP-1 administration [31-33]. Gutderived GLP-1 is able to cross the blood-brain barrier in mice, thus exerting its central activity [34]. In addition, GLP-1 receptor agonists may play a protective role against Alzheimer's disease (AD). In mouse models of AD, GLP-1 receptor activating drugs exerts favorable effects on synaptogenesis, neurogenesis, cell repair, and inflammation reduction [35]. Liraglutide, an agonist of GLP-1, in AD mouse model, was found to prevent synapse loss and deterioration of synaptic plasticity in the hippocampus [36]. Similarly, overall $\beta$-amyloid plaque count in the cortex and dense-core plaque numbers were reduced, together with soluble amyloid oligomers. Such beneficial effect was evident even on cognitive function; in fact, liraglutide-treated $\mathrm{AD}$ animals' recognition memory was restored, while saline-treated $\mathrm{AD}$ mice failed to discriminate between novel and familiar objects. Also, liraglutidetreated AD mice learned the Morris water maze task faster with significantly reduced escape latencies compared with saline-treated controls and liraglutide-treated mice remembered the exact location of the platform after the reversal task, while the saline-treated AD group did not [36]. Moreover, liraglutide and other GLP-1 analogs' administration enhanced synaptic plasticity in area CA1 of the hippocampus in rats, therefore suggesting that GLP-1 therapy could potentially ameliorate the impaired neuronal communication in AD [37]. Recent findings also point out that liraglutide decreases the hyperphosphorylation of tau and neurofilament proteins in the brain and improves the learning and memory ability in mice models of $\mathrm{AD}[38$, 39].

Some works have also shown protective effects of GLP1 agonists against Parkinson's disease (PD). In animal models of PD, treatment with exendin-4, a GLP-1 receptor agonist, promoted adult neurogenesis both in vitro and in vivo, normalized dopamine imbalance, and increased the number of cells positive for markers of dopaminergic neurons in the substantia nigra [40]. Similarly, Li and colleagues found that exendin- 4 administration protected dopaminergic neurons against degeneration, preserved dopamine levels, and improved motor function [41]. In addition, Harkavyi et al. [42] suggested that exendin-4 may pharmacologically arrest and possibly reverse lesions of the nigrostriatal system. In human subjects, a proof-ofconcept study evaluated the progress of 45 patients affected by $\mathrm{PD}$, who were randomly assigned to receive exenatide, that is a GLP-1 agonist, or to act as controls. Single-blinded rating of the exenatide group suggested improvements in PD across motor and cognitive measures compared to controls [43].

Furthermore, GLP-1 analogs might be useful in the treatment of amyotrophic lateral sclerosis (ALS). Li et al. assessed the therapeutic potential of exendin- 4 in both cell culture and in vivo models of ALS and they found that exendin- 4 proved to be neurotrophic in NSC-19 cells, by elevating choline acetyltransferase activity, as well as neuroprotective, by protecting cells from hydrogen peroxide-induced oxidative stress and staurosporine-induced apoptosis. In addition, exendin-4 attenuated neuronal cell death and immunohistochemical analysis demonstrated the 
rescue of neuronal markers associated with motoneurons [44]. Also, another study assessed the effects of intracerebroventricular injection of GLP-1 releasing mesenchymal stromal cells (MSC) in a mouse model of ALS, finding that treatment prolonged survival, delayed symptom onset and weight loss and led to improvements in motor performance tests compared to vehicle-treated controls [45]. Furthermore, in an ALS in vitro model, some authors examined the neuroprotective effects of the administration of $\mathrm{N}$ acetyl-GLP-1(7-34) amide ( $N$-ac-GLP-1), an analog of GLP-1, finding that this compound attenuates intracellular calcium transients, thus counteracting, by preventing exocytosis, glutamate-induced apoptosis and ALS-related metabolic disturbances [46].

Finally, GLP-1 analogs may even be useful in stroke therapy, as evidence collected in rodent models of cerebral ischemia indicates that exendin-4 treatment reduces the damaged brain area and cellular apoptosis, improves the functional motor outcome and neuronal survival rate as well as suppresses oxidative stress, inflammatory response and cell death after reperfusion [41, 47-49] (Fig. 1; Table 1).

\section{GLP-1 and body weight}

GLP-1 is involved in a wide variety of physiological functions, including the regulation of food intake, taste sensitivity, satiation and gastric emptying as well. Thus, GLP-1 system constitutes an interesting candidate as potential target for new anti-obesity drugs. Indeed, more than 160 clinical trials, in which impact of GLP-1 derivatives and analogs on obesity is directly or indirectly investigated, have been registered, so far, on Clinicaltrials.gov.

Clinical experience provides convincing evidence that treatment with GLP-1R agonists results in clinically relevant beneficial effects on body weight [28, 50, 51]. This has consistently been shown during treatment with shortacting and long-acting GLP-1RA in both T2DM and obese individuals [29]. Nine trials meta-analyzed by Monami et al. showed that treatment with GLP-1 receptor agonists for 6 months led to a significant reduction of $\mathrm{BMI}$, in comparison with placebo $\left[-0.96(-1.32,-0.59) \mathrm{kg} / \mathrm{m}^{2}\right.$, $P<0.001$ ] [51]. Moreover, the observed GLP-1RA-related weight loss was associated with reduction in total body fat, particularly trunk or visceral fat [52-56].

It is reasonable that the treatment-related body weight loss can rather be attributed to a decrease in energy intake. In fact, even if in mice model, GLP-1 seems to affect energy expenditure by increased brown adipose tissue thermogenesis [57, 58], the reported effects of GLP-1 on energy expenditure in humans are more inconsistent and conflicting [59-61].
GLP-1 receptors are found in various regions of the brain [62] and, when activated, are believed to promote feeling of satiety, which in combination with GLP-1induced inhibition of gastrointestinal motility reduces food intake and body weight $[63,64]$. In fact, several studies have demonstrated that GLP-1 promotes satiety and suppresses energy intake both in animals [17, 65-68] and human subjects [63, 69-72]. In a meta-analysis of studies in humans evaluating acute effects of GLP-1 infusion on food intake, a mean decrease of $11.7 \%$ in the amount of ad libitum energy intake compared with saline [71] was reported. GLP-1 receptors are expressed in vagal afferent neurons and total subdiaphragmatic or specific afferent vagotomy has been demonstrated to significantly attenuate the satiety effects of intraperitoneally administered GLP-1 [73]. It is likely that GLP-1 acts on vagal afferent terminals in close approximation to the entero-endocrine $\mathrm{L}$ cells, suggesting that vagal-brainstem-hypothalamic pathway may play a critical role in the effects of GLP-1 on food intake [31].

GLP-1 is known to delay gastric emptying, inhibit antral contractility, decrease fasting tone of the proximal stomach and enhance gastric accommodation [74-76]. Acute administration of GLP-1 fully inhibited gastric emptying [77, 78] as well as exenatide, liraglutide and lixisenatide are also known to slow down the rate of gastric emptying [79-81]. However, although gastric motility has been reported to be a key mediator of hunger, satiation and satiety [82], GLP-1R agonism-induced deceleration of gastric emptying and occasional nausea could contribute to the weight reducing effects, but seem to play a minor and often temporary role [29].

Noteworthy, GLP-1 signaling plays an important role in the modulation of taste sensitivity. Data in GLP-1R knockout mice model indicate that GLP-1 signaling normally acts to enhance or maintain sweet taste sensitivity, while GLP-1 $\mathrm{R}^{-1-}$ mice were much more sensitive to the umami stimulus (savory taste) by monosodium glutamate [22] and sour taste [83]. These data suggest a relationship between the modulation of peripheral sensory function and the metabolic response to food intake which could have an impact on eating behavior and hence on weight balance. Interestingly, liraglutide significantly decreased the scores for external eating behavior and food preference [55].

In addition, the relative abundance of GLP- 1 receptors in human adipose tissue may suggest a direct action of this peptide in the metabolism of adipose tissue, and hence on weight regulation [84, 85]. Studies performed in isolated rat and human adipocytes have demonstrated that GLP-1 may exert a dose-dependent dual action, with predominant lipogenic activity when used at picomolar concentrations or lipolytic activity when used at nanomolar doses [86-90]. However, the effects of GLP-1 in adipose tissue have been 
poorly studied and the effective role of this interaction on weight regulation remains to be explored.

It is worth noting that, currently, GLP-1RA have not been officially approved for the treatment of obesity even though peripheral administration of GLP-1 derivatives and analogs to man have shown relevant effects on food intake and body weight suggesting that such therapies could be employed also in the treatment of obesity (Fig. 1; Table 1).

\section{GLP-1 and cardiovascular system}

GLP-1 has been extensively studied in last years in the setting of diabetes mellitus for the improvement of glycemic control. Up to now, growing interest rises on interaction between GLP-1 and cardiovascular system. In fact, experimental studies and clinical data have suggested possible cardiometabolic positive effects of GLP-1, by demonstrating the improvement of cardiac function in patients with heart failure [91]. Thus, it seems that GLP-1 protects heart against acute myocardial ischemic injury [92].

The GLP-1 receptors are widely distributed in several tissues both in animals and humans. Recently, their presence is demonstrated also in myocardium tissue [93, 94]. GLP-1 and GLP-1 agonist bind these receptors, but both in vivo and in vitro studies provide confounding results. These may be explained by the type of GLP-1 agonists and by their different duration of action. Up to now, a complete understanding of the mechanism of GLP-1 actions on myocardial glucose uptake remains far to be comprised.

Notwithstanding the wide evidence of GLP-1 action in diabetic patients, limited is the knowledge on its effects on cardiovascular system. Both GLP-1 and GLP-1 receptor agonist increase blood pressure and cardiac frequency in a rat model [95, 96]. GLP-1 infusion showed a marked improvement in cardiac performance in dogs with dilated cardiomyopathy [97]. The activation of GLP-1 receptor in isolated rat hearts mitigated myocardial injury and improved end-diastolic pressure as well as rate pressure, through a direct effect on cardiovascular cells and pathway [98]. This myocardial improvement was related to a significant reduction in myocardial necrosis, with a consequent reduction of infarct size [98]. In addition GLP-1 has been shown to improve heart recovery and function after ischemia and to promote cell survival preventing oxidative stress-mediated apoptosis in human progenitor cardiac cells [99]. These effects seem to be explained by the increased myocardial glucose uptake induced by GLP-1, with a consequent overcoming insulin resistance under ischemic condition. Furthermore, GLP-1 infusion in rat models seems to attenuate the development of hypertension $[100,101]$, and to reduce oxidative stress and inflammatory state on endothelial cells [102, 103]. Finally, GLP-1 could prevent the development of atherosclerotic lesions by suppressing macrophage foam cell formation [104].

These promising results in animal models suggest that therapy with GLP-1 receptor agonist in humans may preserve cardiomyocyte viability, increase metabolic efficiency and inhibit remodeling occurring in the ischemic heart. Phase 2 trials of GLP-1 in human with cardiovascular diseases seem to confirm these protective effects of incretins [97, 105, 106]. A GLP-1 infusion for $72 \mathrm{~h}$ in patients with myocardial infarction improves left ventricular function, reducing hospital stay and mortality, independently from myocardial infarction location or diabetes history [106]. Furthermore, a GLP-1 long-term infusion improves functional heart capacity and diastolic dysfunction, both in diabetic and non-diabetic patients $[15,105$, 107, 108]. Gejl et al. [109] have demonstrated that GLP-1 did not induce the overall myocardial glucose uptake, but promote changes in the myocardial glucose uptake dependent on the rate of baseline glucose uptake. Fonseca et al. [110] have demonstrated that 26 weeks of treatment with incretins in diabetic patients, significantly reduced lipid asset and cardiovascular risk biomarkers, such as brain natriuretic protein (BNP), plasminogen activator inhibitor (PAI)-1 and high-sensitivity C-reactive protein (CRP). Lønborg et al. [111] have demonstrated that intravenous administration of low-dose of GLP-1 receptor agonist at the time of reperfusion in patients with STsegment elevation myocardial infarction undergoing primary percutaneous coronary intervention, increased myocardial salvage and smaller infarct size. Recently, Monami et al. [92] analyzed all these results in a comprehensive meta-analysis in which all GLP-1 receptor agonist classes showed a significant lower incidence of major cardiovascular events, myocardial infarction and cardiovascular mortality than placebo. Furthermore, ongoing clinical trials have been designed to evaluate cardiovascular endpoints during use of GLP-1 receptor agonists. Finally, GLP-1 receptor agonists are able to reduce endothelial dysfunction in clinical trials involving diabetic patients, considering intima-media thickness that is a recognized marker of subclinical atherosclerosis [112].

However, confusing results are present in the literature on the chronic use of dipeptidyl peptidase-4 inhibitors (DDP4i) that increase GLP-1 serum levels. A recent metaanalysis showed that the chronic use of DDP4i was associated to an increased risk of heart failure, without any clear difference among drugs of this class [113]. This result could be due to differences in patients enrolled in trials evaluating cardiovascular outcome [113]. In fact, these trials enrolled older patients, with a longer duration of diabetes, poorer renal function than other trials [113]. On the other hand, another meta-analysis showed that DDP4i 
use was not related to cardiovascular harm than placebo [114]. Given these challenging results, new trials are needed to completely understand the effect of DDP4i on cardiovascular outcomes.

In conclusion, preclinical and proof-of-concept trials demonstrate that the activation of GLP-1 receptors on cardiomyocytes increases glucose uptake, protecting myocardial cells against apoptosis throughout a series of downstream pathways. However, the mechanism by which GLP-1 receptor activation leads to a myocardial protection remains unclear. At the same time, the potential, beneficial hemodynamic effects of GLP-1 remain to be elucidated and large prospective trials on cardiovascular outcomes are needed to demonstrate the efficacy of GLP-1 in diabetic and pre-diabetic patients (Fig. 1; Table 1).

\section{GLP-1 and bone metabolism}

Food intake may influence the circadian rhythm of bone turnover markers. It has been suggested that bone formation and resorption markers are both lower in the fed state, although the underlying mechanism remains unclear and the clinical impact is small and largely unpredictable [115]. Moreover, the circadian variation in bone resorption, with the peak during the night, could be determined, even only in part, by the nightly fast [116].

These first observations have suggested a potential role on bone turnover of GLP-1 and other hormones released after absorption of nutrients.

In mouse model, genetic disruption of pancreatic GLP-1 receptor led to cortical osteopenia and bone fragility, as well as increased osteoclastic numbers and bone resorption. GLP-1 did not show direct effects on osteoclasts and osteoblasts, however, GLP-1 $\mathrm{R}^{-1-}$ mice exhibited higher levels of urinary deoxypyridinoline; a marker of bone resorption, and reduced levels of calcitonin mRNA transcripts in the thyroid. Moreover, calcitonin treatment effectively suppressed urinary levels of deoxypyridinoline in GLP-1 $\mathrm{R}^{-1-}$, mice and the GLP-1 receptor agonist exendin-4 increased calcitonin gene expression in the thyroid of wild-type mice [14]. Therefore, GLP-1 receptor signaling demonstrates to be effective in the control of bone resorption through a calcitonin-dependent pathway. In both insulin-resistant and type 2 diabetic rat models, GLP-1 exerts a normalizing effect on their impaired bone structure. Overall in mouse models GLP-1 appears to have a double effect on bone metabolism, one direct and another indirect, the latter via thyroid C cells [117]. Furthermore it seems to improve bone strength [118]. In human tissues the G protein-coupled GLP-1 receptor is expressed on osteoblastic precursor cells and studies in vitro demonstrate that GLP-1 can functionally interact with human osteoblasts through a receptor different from the GLP-1 receptor described for pancreas [26] (Fig. 1; Table 1).

\section{GLP-1 and skin}

The effect of GLP-1 on skin was suggested by a study performed in mice that expressed the GLP-1 receptor in the hair follicles, as well as in cultures of skin-derived cells that also express nestin, a marker of cultured cells that have dedifferentiated by epithelial to mesenchymal transition. In humans, the effect of GLP-1 on skin was suggested by the beneficial effect of GLP-1 agonists in patients with both psoriasis and type 2 diabetes. Psoriasis is a common skin disease characterized by chronic inflammation, different degrees of scaling, erythema, itching, and plaque formation. Psoriasis has been demonstrated to have a tight association with increased rates of cardiovascular disease, obesity and type 2 diabetes, conditions characterized by enhanced local and/or systemic inflammation [119]. The improvement of psoriasis was immediately shown after the initiation of therapy with both liraglutide and exenatide $[120,121]$. A prospective cohort study performed in patients with both psoriasis and diabetes reported an improvement of psoriasis after 10 weeks of treatment with liraglutide hypothesizing that it may be due to the ability of GLP-1 to increase circulating iNKT cell number and to modulate monocyte cytokine secretion [122]. A possible explanation of the beneficial effect of GLP-1 agonists on psoriasis may be provided by Faurschou et al. [123] that found an increased presence of GLP-1Rs in psoriasis plaque, likely due to infiltration with immune cells, compared to skin of healthy subjects. Buysschaert et al. [124] demonstrated that this favorable outcome was associated with a decrease of dermal $\gamma \delta$ T cells number and IL-17 expression in psoriasis lesions. However, further studies are needed to establish long-term efficacy of GLP-1 agonists in diabetic patients with psoriasis (Fig. 1; Table 1).

\section{Conclusion}

Research results obtained to date have shown that GLP-1 action is much broader than supposed. In fact, a beneficial effect of GLP-1 has been demonstrated on body weight, bone regulation, cardiovascular system, skin and nervous central system. Based on these assumptions, extra-pancreatic effects of GLP-1 need to be further investigated to clarify its effects on both diabetes-related complications independently of glycemic control and disease beyond type 2 diabetes. Results of these clinical investigations may allow to extend the future clinical use of GLP-1 analogs beyond glycemic control. 
Acknowledgments This review was conceived in the context of the activity of Engioi Club (Italian Society of Endocrinology-SIE). The Authors wish to thank Italian Society of Endocrinology (SIE), Prof Alessandro Peri and Prof Luigi Bartalena for supporting the initiative.

Conflict of interest All authors have no potential conflict of interest to disclose.

\section{References}

1. Holst JJ (2007) The physiology of glucagon-like peptide 1 . Physiol Rev 87:1409-1439. doi:10.1152/physrev.00034.2006

2. Lamont BJ, Li Y, Kwan E et al (2012) Pancreatic GLP-1 receptor activation is sufficient for incretin control of glucose metabolism in mice. J Clin Invest 122:388-402

3. D'Alessio DA, Kahn SE, Leusner CR, Ensinck JW (1994) Glucagon-like peptide 1 enhances glucose tolerance both by stimulation of insulin release and by increasing insulin-independent glucose disposal. J Clin Invest 93:2263-2266. doi:10. 1172/JCI117225

4. Chai W, Zhang X, Barrett EJ, Liu Z (2014) Glucagon-like peptide 1 recruits muscle microvasculature and improves insulin's metabolic action in the presence of insulin resistance. Diabetes

5. Hare KJ, Knop FK, Asmar M et al (2009) Preserved inhibitory potency of GLP-1 on glucagon secretion in type 2 diabetes mellitus. J Clin Endocrinol Metab 94:4679-4687

6. Creutzfeldt WO, Kleine N, Willms B et al (1996) Glucagonostatic actions and reduction of fasting hyperglycemia by exogenous glucagon-like peptide I(7-36) amide in type I diabetic patients. Diabetes Care 19:580-586

7. Nauck MA, Niedereichholz U, Ettler R et al (1997) Glucagonlike peptide 1 inhibition of gastric emptying outweighs its insulinotropic effects in healthy humans. Am J Physiol 273:981-988

8. Blundell JE, Naslund E (1999) Glucagon-like peptide-1, satiety and appetite control. Br J Nutr 81:259-260

9. Pyke C, Heller RS, Kirk RK et al (2014) GLP-1 receptor localization in monkey and human tissue: novel distribution revealed with extensively validated monoclonal antibody. Endocrinology 155:1280-1290

10. Mikhail N (2014) Effects of incretin-based therapy in patients with heart failure and myocardial infarction. Endocrine. doi:10. 1007/s12020-014-0175-4

11. Barrera JG, Sandoval DA, D'Alessio DA, Seeley RJ (2011) GLP-1 and energy balance: an integrated model of short-term and long-term control. Nat Rev Endocrinol 7:507-516. doi:10. 1038/nrendo.2011.77

12. Hsieh J, Longuet C, Baker CL et al (2010) The glucagon-like peptide 1 receptor is essential for postprandial lipoprotein synthesis and secretion in hamsters and mice. Diabetologia 53:552-561

13. Imeryuz N, Yegen BC, Bozkurt A et al (1997) Glucagon-like peptide-1 inhibits gastric emptying via vagal afferent-mediated central mechanisms. Am J Physiol 273:920-927

14. Yamada C, Yamada Y, Tsukiyama K et al (2008) The murine glucagon-like peptide-1 receptor is essential for control of bone resorption. Endocrinology 149:574-579

15. Seufert J, Gallwitz B (2013) The extra-pancreatic effects of GLP-1 receptor agonists: a focus on the cardiovascular, gastrointestinal and central nervous systems. Diabetes Obes Metab

16. Seino Y, Fukushima M, Yabe D (2010) GIP and GLP-1, the two incretin hormones: similarities and differences. J Diabetes Investig 1:8-23. doi:10.1111/j.2040-1124.2010.00022.x
17. Turton MD, O’Shea D, Gunn I et al (1996) A role for glucagonlike peptide- 1 in the central regulation of feeding. Nature 379:69-72. doi:10.1038/379069a0

18. Alhadeff AL, Rupprecht LE, Hayes MR (2012) GLP-1 neurons in the nucleus of the solitary tract project directly to the ventral tegmental area and nucleus accumbens to control for food intake. Endocrinology 153:647-658

19. Dossat AM, Lilly N, Kay K, Williams DL (2011) Glucagon-like peptide 1 receptors in nucleus accumbens affect food intake. J Neurosci 31:14453-14457

20. Bullock BP, Heller RS, Habener JF (1996) Tissue distribution of messenger ribonucleic acid encoding the rat glucagon-like peptide-1 receptor. Endocrinology 137:2968-2978

21. Arakawa M, Mita T, Azuma K et al (2010) Inhibition of monocyte adhesion to endothelial cells and attenuation of atherosclerotic lesion by a glucagon-like peptide-1 receptor agonist, exendin-4. Diabetes 59:1030-1037. doi:10.2337/db09-1694

22. Martin B, Dotson CD, Shin Y-K et al (2009) Modulation of taste sensitivity by GLP-1 signaling in taste buds. Ann N Y Acad Sci 1170:98-101. doi:10.1111/j.1749-6632.2009.03920.x

23. Lankat-Buttgereit B, Goke R, Fehmann HC et al (1994) Molecular cloning of a cDNA encoding for the GLP-1 receptor expressed in rat lung. Exp Clin Endocrinol 102:341-347

24. Liberman A, Esser M, Marx N, Burgmaier M (2013) Glucagonlike peptide-1(9-36) inhibits chemokine-induced migration of human CD4-positive lymphocytes. PLoS One 8:e58445. doi:10. 1371/journal.pone.0058445

25. Ussher JR, Drucker DJ (2014) Cardiovascular actions of incretin-based therapies. Circ Res 114:1788-1803. doi:10.1161/CIR CRESAHA.114.301958

26. Nuche-Berenguer B, Portal-Nunez S, Moreno P et al (2010) Presence of a functional receptor for GLP-1 in osteoblastic cells, independent of the cAMP-linked GLP-1 receptor. J Cell Physiol 225:585-592

27. Seufert J, Gallwitz B (2014) A focus on the cardiovascular, gastrointestinal and central nervous systems. Diabetes Obes Metab 16(8):673-688. doi:10.1111/dom.12251

28. Vilsboll T, Christensen M, Junker AE et al (2012) Effects of glucagon-like peptide-1 receptor agonists on weight loss: systematic review and meta-analyses of randomised controlled trials. BMJ (Clinical Res ed) 344:d7771. doi:10.1136/bmj. d7771

29. Van Bloemendaal L, Ten Kulve JS, la Fleur SE et al (2014) Effects of glucagon-like peptide 1 on appetite and body weight: focus on the CNS. J Endocrinol 221:T1-T16. doi:10.1530/JOE13-0414

30. Vahl TP, Tauchi M, Durler TS et al (2007) Glucagon-like peptide-1 (GLP-1) receptors expressed on nerve terminals in the portal vein mediate the effects of endogenous GLP-1 on glucose tolerance in rats. Endocrinology 148:4965-4973

31. Abbott CR, Monteiro M, Small CJ et al (2005) The inhibitory effects of peripheral administration of peptide YY(3-36) and glucagon-like peptide- 1 on food intake are attenuated by ablation of the vagal-brainstem-hypothalamic pathway. Brain Res 1044:127-131. doi:10.1016/j.brainres.2005.03.011

32. Fujiwara K, Gotoh K, Chiba S et al (2012) Intraportal administration of DPP-IV inhibitor regulates insulin secretion and food intake mediated by the hepatic vagal afferent nerve in rats. J Neurochem 121:66-76

33. Hayes MR, Kanoski SE, De Jonghe BC et al (2011) The common hepatic branch of the vagus is not required to mediate the glycemic and food intake suppressive effects of glucagon-like-peptide-1. Am J Physiol Regul Integr Comp Physiol 301:1479-1485

34. Kastin AJ, Akerstrom V, Pan W (2002) Interactions of glucagon-like peptide-1 (GLP-1) with the blood-brain barrier. J Mol Neurosci 18:7-14 
35. Hölscher C (2012) Potential role of glucagon-like peptide-1 (GLP-1) in neuroprotection. CNS Drugs 26:871-882. doi:10. 2165/11635890-000000000-00000

36. McClean PL, Parthsarathy V, Faivre E, Holscher C (2011) The diabetes drug liraglutide prevents degenerative processes in a mouse model of Alzheimer's disease. J Neurosci 31:6587-6594

37. McClean PL, Gault VA, Harriott P, Hölscher C (2010) Glucagon-like peptide-1 analogues enhance synaptic plasticity in the brain: a link between diabetes and Alzheimer's disease. Eur J Pharmacol 630:158-162. doi:10.1016/j.ejphar.2009.12.023

38. Xiong H, Zheng C, Wang J et al (2013) The neuroprotection of liraglutide on Alzheimer-like learning and memory impairment by modulating the hyperphosphorylation of tau and neurofilament proteins and insulin signaling pathways in mice. J Alzheimers Dis 37:623-635

39. Yang Y, Zhang J, Ma D et al (2013) Subcutaneous administration of liraglutide ameliorates Alzheimer-associated tau hyperphosphorylation in rats with type 2 diabetes. J Alzheimers Dis 37:637-648

40. Bertilsson G, Patrone C, Zachrisson O et al (2008) Peptide hormone exendin- 4 stimulates subventricular zone neurogenesis in the adult rodent brain and induces recovery in an animal model of Parkinson's disease. J Neurosci Res 86:326-338

41. Li Y, Perry T, Kindy MS et al (2009) GLP-1 receptor stimulation preserves primary cortical and dopaminergic neurons in cellular and rodent models of stroke and Parkinsonism. Proc Natl Acad Sci USA 106:1285-1290. doi:10.1073/pnas.0806720106

42. Harkavyi A, Abuirmeileh A, Lever R et al (2008) Glucagon-like peptide 1 receptor stimulation reverses key deficits in distinct rodent models of Parkinson's disease. J Neuroinflamm 5:19

43. Aviles-Olmos I, Dickson J, Kefalopoulou Z et al (2013) Exenatide and the treatment of patients with Parkinson's disease. J Clin Invest 123:2730-2736

44. Li Y, Chigurupati S, Holloway HW et al (2012) Exendin-4 ameliorates motor neuron degeneration in cellular and animal models of amyotrophic lateral sclerosis. PLoS One 7(2):e32008. doi:10.1371/journal.pone.0032008

45. Knippenberg S, Thau N, Dengler R et al (2012) Intracerebroventricular injection of encapsulated human mesenchymal cells producing glucagon-like peptide 1 prolongs survival in a mouse model of ALS. PLoS One 7

46. Sun H, Knippenberg S, Thau N et al (2013) Therapeutic potential of $\mathrm{N}$-acetyl-glucagon-like peptide- 1 in primary motor neuron cultures derived from non-transgenic and SOD1-G93A ALS mice. Cell Mol Neurobiol 33:347-357

47. Lee CH, Yan B, Yoo K-Y et al (2011) Ischemia-induced changes in glucagon-like peptide-1 receptor and neuroprotective effect of its agonist, exendin-4, in experimental transient cerebral ischemia. J Neurosci Res 89:1103-1113

48. Teramoto S, Miyamoto N, Yatomi K et al (2011) Exendin-4, a glucagon-like peptide-1 receptor agonist, provides neuroprotection in mice transient focal cerebral ischemia. J Cereb Blood Flow Metab 31:1696-1705

49. Wang M-D, Huang Y, Zhang G-P et al (2012) Exendin-4 improved rat cortical neuron survival under oxygen/glucose deprivation through PKA pathway. Neuroscience 226:388-396

50. Monami M, Marchionni N, Mannucci E (2009) Glucagon-like peptide- 1 receptor agonists in type 2 diabetes: a meta-analysis of randomized clinical trials. Eur J Endocrinol 160:909-917. doi:10.1530/EJE-09-0101

51. Monami M, Dicembrini I, Marchionni N et al (2012) Effects of glucagon-like peptide-1 receptor agonists on body weight: a meta-analysis. Exp Diabetes Res 2012:672658. doi:10.1155/ 2012/672658

52. Jendle J, Nauck MA, Matthews DR et al (2009) Weight loss with liraglutide, a once-daily human glucagon-like peptide-1 analogue for type 2 diabetes treatment as monotherapy or added to metformin, is primarily as a result of a reduction in fat tissue. Diabetes Obes Metab 11:1163-1172. doi:10.1111/j.1463-1326. 2009.01158.x

53. Jensterle Sever M, Kocjan T, Pfeifer M et al (2014) Short-term combined treatment with liraglutide and metformin leads to significant weight loss in obese women with polycystic ovary syndrome and previous poor response to metformin. Eur $\mathbf{J}$ Endocrinol 170:451-459. doi:10.1530/EJE-13-0797

54. Li C, Li J, Zhang Q et al (2012) Efficacy and safety comparison between liraglutide as add-on therapy to insulin and insulin dose-increase in Chinese subjects with poorly controlled type 2 diabetes and abdominal obesity. Cardiovasc Diabetol 11:142. doi:10.1186/1475-2840-11-142

55. Inoue K, Maeda N, Kashine S et al (2011) Short-term effects of liraglutide on visceral fat adiposity, appetite, and food preference: a pilot study of obese Japanese patients with type 2 diabetes. Cardiovasc Diabetol 10:109. doi:10.1186/1475-2840-10109

56. Dushay J, Gao C, Gopalakrishnan GS et al (2012) Short-term exenatide treatment leads to significant weight loss in a subset of obese women without diabetes. Diabetes Care 35:4-11. doi:10. 2337/dc11-0931

57. Osaka T, Endo M, Yamakawa M, Inoue S (2005) Energy expenditure by intravenous administration of glucagon-like peptide-1 mediated by the lower brainstem and sympathoadrenal system. Peptides 26:1623-1631. doi:10.1016/j.peptides.2005.02.016

58. Lockie SH, Heppner KM, Chaudhary N et al (2012) Direct control of brown adipose tissue thermogenesis by central nervous system glucagon-like peptide-1 receptor signaling. Diabetes 61:2753-2762. doi:10.2337/db11-1556

59. Horowitz M, Flint A, Jones KL et al (2012) Effect of the oncedaily human GLP-1 analogue liraglutide on appetite, energy intake, energy expenditure and gastric emptying in type 2 diabetes. Diabetes Res Clin Pract 97:258-266. doi:10.1016/j.dia bres.2012.02.016

60. Harder H, Nielsen L, Thi TDT, Astrup A (2004) The effect of liraglutide, a long-acting glucagon-like peptide 1 derivative, on glycemic control, body composition, and 24-h energy expenditure in patients with type 2 diabetes. Diabetes Care 27:1915-1921. doi:10.2337/diacare.27.8.1915

61. Bradley DP, Kulstad R, Racine N et al (2012) Alterations in energy balance following exenatide administration. Appl Physiol Nutr Metab 37:893-899. doi:10.1139/h2012-068

62. Göke R, Larsen PJ, Mikkelsen JD, Sheikh SP (1995) Distribution of GLP-1 binding sites in the rat brain: evidence that exendin- 4 is a ligand of brain GLP-1 binding sites. Eur J Neurosci 7:2294-2300

63. Flint A, Raben A, Astrup A, Holst JJ (1998) Glucagon-like peptide 1 promotes satiety and suppresses energy intake in humans. J Clin Invest 101:515-520

64. Giorgino F, Leonardini A, Natalicchio A, Laviola L (2011) Multifactorial intervention in type 2 diabetes: the promise of incretin-based therapies. J Endocrinol Invest 34:69-77. doi:10. $3275 / 7444$

65. Raun K, von Voss P, Knudsen LB (2007) Liraglutide, a once-daily human glucagon-like peptide-1 analog, minimizes food intake in severely obese minipigs. Obes (Silver Spring) 15:1710-1716

66. Raun K, von Voss P, Gotfredsen CF et al (2007) Liraglutide, a long-acting glucagon-like peptide-1 analog, reduces body weight and food intake in obese candy-fed rats, whereas a dipeptidyl peptidase-IV inhibitor, vildagliptin, does not. Diabetes 56:8-15

67. Kinzig KP, D’Alessio DA, Seeley RJ (2002) The diverse roles of specific GLP-1 receptors in the control of food intake and the response to visceral illness. J Neurosci 22:10470-10476 
68. Tang-Christensen M, Larsen PJ, Göke R et al (1996) Central administration of GLP-1-(7-36) amide inhibits food and water intake in rats. Am J Physiol 271:R848-R856

69. Toft-Nielsen MB, Madsbad S, Holst JJ (1999) Continuous subcutaneous infusion of glucagon-like peptide 1 lowers plasma glucose and reduces appetite in type 2 diabetic patients. Diabetes Care 22:1137-1143

70. Gutzwiller JP, Drewe J, Goke B et al (1999) Glucagon-like peptide-1 promotes satiety and reduces food intake in patients with diabetes mellitus type 2. Am J Physiol 276:1541-1544

71. Verdich C, Flint A, Gutzwiller JP et al (2001) A meta-analysis of the effect of glucagon-like peptide-1 (7-36) amide on ad libitum energy intake in humans. J Clin Endocrinol Metab 86:4382-4389. doi:10.1210/jcem.86.9.7877

72. Edwards CM, Stanley SA, Davis R et al (2001) Exendin-4 reduces fasting and postprandial glucose and decreases energy intake in healthy volunteers. Am J Physiol Endocrinol Metab 281:E155-E161

73. Rüttimann EB, Arnold M, Hillebrand JJ et al (2009) Intrameal hepatic portal and intraperitoneal infusions of glucagon-like peptide-1 reduce spontaneous meal size in the rat via different mechanisms. Endocrinology 150:1174-1181. doi:10.1210/en. 2008-1221

74. Schirra J, Göke B (2005) The physiological role of GLP-1 in human: incretin, ileal brake or more? Regul Pept 128:109-115. doi:10.1016/j.regpep.2004.06.018

75. Andrews CN, Bharucha AE, Camilleri M et al (2007) Effects of glucagon-like peptide-1 and sympathetic stimulation on gastric accommodation in humans. Neurogastroenterol Motil 19:716-723. doi:10.1111/j.1365-2982.2007.00923.x

76. Schirra J (2002) Effects of glucagon-like peptide-1(7-36) amide on motility and sensation of the proximal stomach in humans. Gut 50:341-348. doi:10.1136/gut.50.3.341

77. Young AA, Gedulin BR, Rink TJ (1996) Dose-responses for the slowing of gastric emptying in a rodent model by glucagon-like peptide (7-36) NH2, amylin, cholecystokinin, and other possible regulators of nutrient uptake. Metabolism 45:1-3

78. Umapathysivam MM, Lee MY, Jones KL et al (2014) Comparative effects of prolonged and intermittent stimulation of the glucagon-like peptide 1 receptor on gastric emptying and glycemia. Diabetes 63:785-790. doi:10.2337/db13-0893

79. Rotondo A, Janssen P, Mulè F, Tack J (2013) Effect of the GLP1 analog liraglutide on satiation and gastric sensorimotor function during nutrient-drink ingestion. Int $\mathrm{J}$ Obes (Lond) 37:693-698. doi:10.1038/ijo.2012.101

80. Madsbad S (2009) Exenatide and liraglutide: different approaches to develop GLP-1 receptor agonists (incretin mimetics)preclinical and clinical results. Best Pract Res Clin Endocrinol Metab 23:463-477. doi:10.1016/j.beem.2009.03.008

81. Van Can J, Sloth B, Jensen CB et al (2013) Effects of the oncedaily GLP-1 analog liraglutide on gastric emptying, glycemic parameters, appetite and energy metabolism in obese, non-diabetic adults. Int J Obes (Lond). doi:10.1038/ijo.2013.162

82. Janssen P, Vanden Berghe P, Verschueren S et al (2011) Review article: the role of gastric motility in the control of food intake. Aliment Pharmacol Ther 33:880-894. doi:10.1111/j.1365-2036. 2011.04609.x

83. YK, Shin, Martin B, Golden E, Dotson CD, Maudsley S, Kim W, Jang HJ, Mattson MP, Drucker DJ, Egan JM MS, Shin Y-K, Martin B et al (2008) Modulation of taste sensitivity by GLP-1 signaling. J Neurochem 106:455-63. doi:10.1111/j.1471-4159. 2008.05397.x

84. Merida E, Delgado E, Molina LM et al (1993) Presence of glucagon and glucagon-like peptide-1-(7-36) amide receptors in solubilized membranes of human adipose tissue. J Clin Endocrinol Metab 77:1654-1657
85. Le Kim Chung T, Hosaka T, Yoshida M et al (2009) Exendin-4, a GLP-1 receptor agonist, directly induces adiponectin expression through protein kinase A pathway and prevents inflammatory adipokine expression. Biochem Biophys Res Commun 390:613-618. doi:10.1016/j.bbrc.2009.10.015

86. Perea A, Vinambres C, Clemente F et al (1997) GLP-1 (7-36) amide: effects on glucose transport and metabolism in rat adipose tissue. Horm Metab Res 29:417-421. doi:10.1055/s-2007-979068

87. Ruiz-Grande C, Alarcon C, Merida E, Valverde I (1992) Lipolytic action of glucagon-like peptides in isolated rat adipocytes. Peptides 13:13-16

88. Sancho V, Trigo MV, Gonzalez N et al (2005) Effects of glucagon-like peptide-1 and exendins on kinase activity, glucose transport and lipid metabolism in adipocytes from normal and type-2 diabetic rats. J Mol Endocrinol 35:27-38. doi:10.1677/ jme.1.01747

89. Vendrell J, El Bekay R, Peral B et al (2011) Study of the potential association of adipose tissue GLP-1 receptor with obesity and insulin resistance. Endocrinology 152:4072-4079. doi:10.1210/en.2011-1070

90. Villanueva-Penacarrillo ML, Marquez L, Gonzalez N et al (2001) Effect of GLP-1 on lipid metabolism in human adipocytes. Horm Metab Res 33:73-77

91. Zhao TC (2013) Glucagon-like peptide-1 (GLP-1) and protective effects in cardiovascular disease: a new therapeutic approach for myocardial protection. Cardiovasc Diabetol 12:90. doi:10.1186/1475-2840-12-90

92. Monami M, Dicembrini I, Nardini C et al (2014) Effects of glucagon-like peptide-1 receptor agonists on cardiovascular risk: a meta-analysis of randomized clinical trials. Diabetes Obes Metab 16:38-47. doi:10.1111/dom.12175

93. Wei Y, Mojsov S (1995) Tissue-specific expression of the human receptor for glucagon-like peptide-I: brain, heart and pancreatic forms have the same deduced amino acid sequences. FEBS Lett 358:219-224

94. Vila Petroff MG, Egan JM, Wang X, Sollott SJ (2001) Glucagon-like peptide-1 increases cAMP but fails to augment contraction in adult rat cardiac myocytes. Circ Res 89:445-452

95. Barragan JM, Rodriguez RE, Eng J, Blazquez E (1996) Interactions of exendin-(9-39) with the effects of glucagon-like peptide-1-(7-36) amide and of exendin-4 on arterial blood pressure and heart rate in rats. Regul Pept 67:63-68

96. Yamamoto H, Lee CE, Marcus JN et al (2002) Glucagon-like peptide-1 receptor stimulation increases blood pressure and heart rate and activates autonomic regulatory neurons. J Clin Invest 110:43-52

97. Nikolaidis LA, Elahi D, Shen Y-T, Shannon RP (2005) Active metabolite of GLP-1 mediates myocardial glucose uptake and improves left ventricular performance in conscious dogs with dilated cardiomyopathy. Am J Physiol Heart Circ Physiol 289:2401-2408

98. Zhao T, Parikh P, Bhashyam S et al (2006) Direct effects of glucagon-like peptide-1 on myocardial contractility and glucose uptake in normal and postischemic isolated rat hearts. J Pharmacol Exp Ther 317:1106-1113

99. Laviola L, Leonardini A, Melchiorre M et al (2012) Glucagonlike peptide- 1 counteracts oxidative stress-dependent apoptosis of human cardiac progenitor cells by inhibiting the activation of the c-Jun $\mathrm{N}$-terminal protein kinase signaling pathway. Endocrinology 153:5770-5781. doi:10.1210/en.2012-1461

100. Yu M, Moreno C, Hoagland KM et al (2003) Antihypertensive effect of glucagon-like peptide 1 in Dahl salt-sensitive rats. J Hypertens 21:1125-1135

101. Pacheco BP, Crajoinas RO, Couto GK et al (2011) Dipeptidyl peptidase IV inhibition attenuates blood pressure rising in young spontaneously hypertensive rats. J Hypertens 29:520-528 
102. Gaspari T, Liu H, Welungoda I et al (2011) A GLP-1 receptor agonist liraglutide inhibits endothelial cell dysfunction and vascular adhesion molecule expression in an ApoE-/- mouse model. Diab Vasc Dis Res 8:117-124. doi:10.1177/1479164111404257

103. Han L, Yu Y, Sun X, Wang B (2012) Exendin-4 directly improves endothelial dysfunction in isolated aortas from obese rats through the cAMP or AMPK-eNOS pathways. Diabetes Res Clin Pract 97:453-460. doi:10.1016/j.diabres.2012.04.001

104. Tashiro Y, Sato K, Watanabe T et al (2014) A glucagon-like peptide-1 analog liraglutide suppresses macrophage foam cell formation and atherosclerosis. Peptides 54C:19-26

105. Sokos GG, Nikolaidis LA, Mankad S et al (2006) Glucagon-like peptide-1 infusion improves left ventricular ejection fraction and functional status in patients with chronic heart failure. J Card Fail 12:694-699

106. Sokos GG, Bolukoglu H, German J et al (2007) Effect of glucagon-like peptide-1 (GLP-1) on glycemic control and left ventricular function in patients undergoing coronary artery bypass grafting. Am J Cardiol 100:824-829. doi:10.1016/j.amj card.2007.05.022

107. Read PA, Hoole SP, White PA et al (2011) A pilot study to assess whether glucagon-like peptide-1 protects the heart from ischemic dysfunction and attenuates stunning after coronary balloon occlusion in humans. Circ Cardiovasc Interv 4:266-272. doi:10.1161/CIRCINTERVENTIONS.110.960476

108. Read PA, Khan FZ, Dutka DP (2012) Cardioprotection against ischaemia induced by dobutamine stress using glucagon-like peptide-1 in patients with coronary artery disease. Heart 98:408-413. doi:10.1136/hrt.2010.219345

109. Gej1 M, Lerche S, Mengel A et al (2014) Influence of GLP-1 on myocardial glucose metabolism in healthy men during normoor hypoglycemia. PLoS One 9(1):e83758. doi:10.1371/journal. pone.0083758

110. Fonseca VDJH, Bain SC (2011) Liraglutide improves the profile of lipid and cardiovascular risk biomarkers from baseline. In: IDF 2011 21th World Congress Abstract Book Poster vol 135, pp 442-443

111. Lonborg J, Vejlstrup N, Kelbæk H et al (2012) Exenatide reduces reperfusion injury in patients with ST-segment elevation myocardial infarction. Eur Heart J 33:1491-1499

112. Kelly AS, Bergenstal RM, Gonzalez-Campoy JM et al (2012) Effects of exenatide vs. metformin on endothelial function in obese patients with pre-diabetes: a randomized trial. Cardiovasc Diabetol 11:64
113. Monami M, Dicembrini I, Mannucci E (2014) Dipeptidyl peptidase-4 inhibitors and heart failure: a meta-analysis of randomized clinical trials. Nutr Metab Cardiovasc Dis 24(7):689-697. doi:10.1016/j.numecd.2014.01.017

114. Wu S, Hopper I, Skiba M, Krum H (2014) Dipeptidyl peptidase4 inhibitors and cardiovascular outcomes: meta-analysis of randomized clinical trials with 55,141 participants. Cardiovasc Ther 32(4):147-158. doi:10.1111/1755-5922.12075

115. Clowes JA, Hannon RA, Yap TS et al (2002) Effect of feeding on bone turnover markers and its impact on biological variability of measurements. Bone 30:886-890

116. Schlemmer A, Hassager C (1999) Acute fasting diminishes the circadian rhythm of biochemical markers of bone resorption. Eur J Endocrinol 140:332-337

117. Nuche-Berenguer B, Moreno P, Esbrit P et al (2009) Effect of GLP-1 treatment on bone turnover in normal, type 2 diabetic, and insulin-resistant states. Calcif Tissue Int 84:453-461

118. Mabilleau G, Mieczkowska A, Irwin N et al (2013) Optimal bone mechanical and material properties require a functional glucagon-like peptide-1 receptor. J Endocrinol 219:59-68

119. Davidovici BB, Sattar N, Prinz JC et al (2010) Psoriasis and systemic inflammatory diseases: potential mechanistic links between skin disease and co-morbid conditions. J Invest Dermatol 130:1785-1796. doi:10.1038/jid.2010.103

120. Buysschaert M, Tennstedt D, Preumont V (2012) Improvement of psoriasis during exenatide treatment in a patient with diabetes. Diabetes Metab 38:86-88

121. Faurschou A, Knop FK, Thyssen JP et al (2014) Improvement in psoriasis after treatment with the glucagon-like peptide-1 receptor agonist liraglutide. Acta Diabetol 51:147-150. doi:10. 1007/s00592-011-0359-9

122. Ahern T, Tobin A-M, Corrigan M et al (2013) Glucagon-like peptide- 1 analogue therapy for psoriasis patients with obesity and type 2 diabetes: a prospective cohort study. J Eur Acad Dermatol Venereol 27(11):1440-1443. doi:10.1111/j.14683083.2012.04609.x

123. Faurschou A, Pedersen J, Gyldenløve M et al (2013) Increased expression of glucagon-like peptide-1 receptors in psoriasis plaques. Exp Dermatol 22:150-152. doi:10.1111/exd.12081

124. Buysschaert M, Baeck M, Preumont V et al (2014) Improvement of psoriasis during GLP-1 analogue therapy in type 2 diabetes is associated with decreasing dermal $\gamma \delta \mathrm{T}$ cells number: a prospective case series study. Br J Dermatol. doi:10.1111/bjd.12886 